\title{
CHANGES IN METABOLIC EFFICIENCY IN SKILLED ATHLETES DURING INTENSE EXERCISE
}

\author{
Ievgeniia Loshkarova \\ Chief Specialist of Scientific and Organizational Work Department, \\ State Scientific Research Institute of Physical Culture and Sports, Postgraduate student, \\ National University of Physical Education and Sports of Ukraine, Ukraine \\ e-mail: lea.dietdoc@gmail.com, orcid.org/0000- 0001-8057-524x
}

\begin{abstract}
Summary
The body's predominant choice of substrates and the rate of their oxidation in the working muscle are largely influenced by physical activity intensity. The higher the intensity of work, the more important role in energy supply processes are played by carbohydrates. It is suggested that the ability to most effectively use fat as an energy substrate at rest and during exercise allows athletes to save carbohydrates to perform high-intensity work. This study investigated the efficiency of metabolism in skilled athletes at rest and during the exercise of increasing intensity. 99 body composition assessments (via bioelectrical impedance) and 99 incremental exercise tests using a gas analysis system were performed in 90 male national- and international-level athletes (age 16-35 y.o.) of sports related to endurance and combat sports. The respiratory exchange ratio in skilled athletes at rest significantly correlates with the values of respiratory exchange ratio when reaching the anaerobic threshold $((\mathrm{r}=0.52, \mathrm{p} \leq 0,05))$ and respiratory exchange ratio when reaching the maximum oxygen consumption $((\mathrm{r}=0.52$, $\mathrm{p} \leq 0,05))$ and with the maximum oxygen consumption $(\mathrm{r}=-0.26, \mathrm{p} \leq 0,05)$.

The oobtained data shows that efficient resting metabolism creates the preconditions for more efficient use of energy substrates during intense muscle activity. The respiratory exchange ratio is an informative indicator of the efficiency of metabolism, which can be used in the complex control of the functional condition of the athlete.
\end{abstract}

Keywords: metabolism, physical exercise, fat oxidation, carbohydrate oxidation

DOI: https://doi.org/10.23856/4823

\section{Introduction}

Significant energy expenditure due to intense physical activity increases the metabolism of skilled athletes both during physical activity and in their recovery period. Athletes spend at least 1000-2000 kcal per day on physical activity. During intense training, total daily energy expenditure (TDEE) can exceed 10,000 kcal (Burke et al, 2015). However, all essential nutrients - proteins, fats, and carbohydrates - can provide substrates for energy production in muscles. The body's predominant choice of substrates and the rate of their oxidation in the working muscle is influenced by many factors, primarily the duration and intensity of exercise, the athlete's fitness, and nutrition. The intensity of physical activity largely determines the choice of substrates for energy. The higher the intensity of work, the more important role in energy supply processes are played by carbohydrates (Shils\&Shike, 2006).

Recently, the term "metabolic efficiency" has come into use, meaning the ability to most effectively use fat as an energy substrate both at rest and during exercise, thus saving glycogen stores (Seebohar, 2014). It is believed that this type of metabolism allows one to save 
carbohydrates to perform high-intensity work. Most often, the respiratory exchange ratio (RER) is used to assess the use of oxidation substrates, which allows determining the contribution of carbohydrates and fats to the energy supply (Carpenter, 1964). Thus, the value of RER can be considered an informative indicator of metabolic reserves of the athlete.

The study by Helge et al. (1999) demonstrates significant individual variability in the ratio of the use of energy substrates during the same intensity of activity. In this case, physically active and trained people usually have lower RER than untrained during the same activity load (Jeukendrup et al., 1997; Bergman\&Brooks, 1999). In addition, endurance training can reduce the value of RER while also increasing the oxidative activity of enzymes and oxygen consumption, as well as help delay the development of fatigue during exercise (Messonnier et al., 2005). Meanwhile, even athletes who specialize in endurance sports demonstrate great variability of RER at rest and during exercise of varying intensity (Romijin et al., 2000; Carter et al., 2001). The study by Goedecke et al. (2000) has shown significant fluctuations in resting RER in the range from 0.93 to 0.72 , which corresponds to energy production due to fat oxidation from $23 \%$ to $93 \%$.

In the study by Rauch et al. (1999) with the participation of qualified cyclists, it was demonstrated that not all athletes use the same amount of fat as an energy substrate when performing the same work. Athletes whose contribution of carbohydrates to energy production was higher at rest and during exercise showed an earlier development of fatigue compared to those with lower RERs (and consequently a higher contribution of fat to energy production). This is due to their faster depletion of glycogen stores.

Therefore, it is of scientific interest to study the efficiency of athletes' metabolism. The aim of this study is to determine the efficiency of metabolism in skilled athletes at rest and during exercise of increasing intensity.

\section{Materials and methods}

\section{Participants}

99 incremental exercise tests were performed in 90 male national- and international-level athletes (age 16-35 y.o.) of sports related to endurance (biathlon $(n=40)$, triathlon $(n=4)$, rowing $(\mathrm{n}=13)$, canoeing $(\mathrm{n}=12)$, modern pentathlon $(\mathrm{n}=12)$, and combat sports (boxing $[\mathrm{n}=14]$, taekwondo $[\mathrm{n}=4])$.

\section{Procedure}

The study was performed in the morning, 2 hours after breakfast. After measuring anthropometric parameters (length [cm], body mass [kg], and body composition (mass [kg] and percentage of body fat, lean body mass (LBM) $[\mathrm{kg}])$, we performed a test to determine subjects' maximum oxygen uptake $\left(\mathrm{VO}_{2 \max }, \mathrm{ml} \cdot \mathrm{min}^{-1} \cdot \mathrm{kg}^{-1}\right)$.

The test to determine the maximum oxygen consumption $\left(\mathrm{VO}_{2 \max }, \mathrm{ml} \cdot \mathrm{min}^{-1} \cdot \mathrm{kg}^{-1}\right)$, used exercise of increasing intensity on the rowing ergometer Concept II (USA) for rowers, on the manual ergometer Technogym (Italy) for the kayak and canoe athletes, on the LE 500 treadmill, (Viasys Healthcare, Germany) for the biathlon, triathlon, modern pentathlon, boxing, and taekwondo athletes. The exercises lasted until the athletes reached the $\mathrm{VO}_{2 \max }$. The sign of reaching $\mathrm{VO}_{2 \max }$ was the lack of increase in oxygen consumption with increasing power or its fluctuations within $100 \mathrm{ml} \cdot \mathrm{min}^{-1}$. Respiratory system parameters were recorded using an Oxycon mobile gas analyzer (Care fusion, USA; Jeager, Germany). Before performing the test load, a 6-minute warm-up was performed, and after the test was completed, the rate of recovery processes was assessed for three minutes via measurement of heart rate, blood lactate concentration, oxygen consumption, and carbon dioxide excretion. 
The magnitude of the initial exercise load on the Concept rowing ergometer was $1.5 \mathrm{~W} \cdot \mathrm{kg}^{-1}$ body mass, at each subsequent stage the load increased by $30 \mathrm{~W}$; initial load on the running ergometer was $2.0 \mathrm{~W}$ per kg body mass (running speed $-10 \mathrm{~km} \cdot \mathrm{h}^{-1}$ ). The duration of each step of the test load was two minutes (testing on a treadmill) or three minutes (testing on a rowing ergometer).

To assess the effectiveness of metabolic processes, we determined the respiratory exchange ratio, which reflects the use of energy substrates. To find out the changes in the structure of energy expenditure during muscular activity, the RERs of the athletes were examined both at rest and during exercise.

The study determined the following metabolic parameters: intensity;

$\mathrm{VO}_{2}: \mathrm{ml} \cdot \mathrm{min}^{-1} \cdot \mathrm{kg}^{-1}$ - oxygen consumption at rest and during exercise with increasing

$\mathrm{RER}_{\text {rest }}$ - respiratory exchange ratio at rest;

$\mathrm{RER}_{\mathrm{AT}}$ - respiratory exchange ratio when reaching the anaerobic threshold;

$\mathrm{RER}_{\mathrm{VO} 2 \max }$ - respiratory exchange ratio when reaching maximum oxygen consumption;

$\mathrm{Q}, \mathrm{kcal} \cdot \mathrm{min}^{-1}-$ energy consumption;

$\mathrm{Qc}, \mathrm{kcal} \cdot \mathrm{min}^{-1}-$ energy obtained from carbohydrates;

Qf, kcal $\cdot \min ^{-1}-$ energy obtained from fat;

Statistical analysis

The data obtained were analyzed using methods of mathematical statistics: mean values method, correlation analysis, two-way ANOVA post-hoc Tukey test.

\section{Ethics}

The research was conducted following the basic bioethical norms of the Helsinki Declaration of the World Medical Association on Ethical Principles of Scientific and Medical Research, as amended (2000, as amended in 2008), the Universal Declaration on Bioethics and Human Rights (1997), and the Council of Europe Convention on Human Rights and Biomedicine. 1997). Each study participant provided written informed consent to participate in the study.

\section{Results}

RER variability at rest, during anaerobic threshold, and maximum oxygen uptake was recorded (Table 1).

Table 1

RER in skilled endurance athletes at rest, during AT and $\mathrm{VO}_{2 \max }$

\begin{tabular}{|c|c|c|c|}
\hline Condition & $\mathbf{X} \pm \boldsymbol{\partial}$ & $\mathbf{- 9 5 \%}$ & $\mathbf{+ 9 5 \%}$ \\
\hline Resting & $0.81 \pm 0,10$ & 0.79 & 0.83 \\
\hline $\mathrm{AT}$ & $0.96 \pm 0,07$ & 0.95 & 0.97 \\
\hline $\mathrm{VO}_{2 \max }$ & $1.09 \pm 0,09$ & 1.07 & 1.11 \\
\hline
\end{tabular}

In this study, the average value of RER at rest in skilled athletes was $0.81 \pm 0.10$, which corresponds to the use of $65 \%$ of energy from fat, while the range of confidence interval (0.79- 0.83 ) shows that the contribution of fat to production energy at rest ranges from 58-71\%.

The average values of $\mathrm{RER}_{\mathrm{AT}}$ were $0.96 \pm 0.07$, which indicates a $14 \%$ contribution by fat to energy supply. The range of RER oscillations at the level of AT (0.95-0.97) is smaller compared to at resting state and corresponds to a $10-17 \%$ contribution of fat to energy production. 
It is traditionally believed that $100 \%$ of energy at the level of $\mathrm{VO}_{2 \max }$ is provided by carbohydrates $[1,2]$. Our average data $(1.09 \pm 0.09)$ confirms this fact, but there were some athletes for whom RER when reaching their $\mathrm{VO}_{2 \max }$ was $0,96-0.99$, and in some cases 0.93 , which indicates a possible contribution of fat to energy production even during high-intensity exercise.

Energy consumption and use of energy substrates during intense physical activity at the level of $\mathrm{AT}$ and $\mathrm{VO}_{2 \max }$ are in Table 2.

Table 2

Energy expenditure in skilled athletes associated with the manifestation of endurance when reaching the anaerobic threshold and $\mathrm{VO}_{2 \max }(n=99)$

\begin{tabular}{|l|c|c|c|c|}
\hline \multirow{2}{*}{ Measurement } & \multicolumn{2}{|c|}{$\mathbf{A T}$} & \multicolumn{2}{c|}{ VO $_{2 \max }$} \\
\cline { 2 - 5 } & $\mathbf{X} \pm \boldsymbol{\partial}$ & $\mathbf{9 5 \%} \mathbf{C I}$ & $\mathbf{X} \pm \boldsymbol{\partial}$ & $\mathbf{9 5 \%} \mathbf{C I}$ \\
\hline $\mathrm{VO}_{2}, \mathrm{ml} \cdot \mathrm{min}^{-1} \cdot \mathrm{kg}^{-1}$ & $46,93 \pm 8,65$ & $45,21-48,66$ & $56,90 \pm 9,26$ & $55,05-58,75$ \\
\hline $\mathrm{Q}_{\mathrm{k}} \mathrm{kcal} \cdot \mathrm{min}^{-1} \cdot \mathrm{kg}^{-1}$ & $0,22 \pm 0,06$ & $0,21-0,24$ & $0,27 \pm 0,07$ & $0,26-0,29$ \\
\hline $\mathrm{Q}_{\mathrm{c}}, \mathrm{kcal} \cdot \mathrm{min}^{-1} \cdot \mathrm{kg}^{-1}$ & $0,18 \pm 0,06$ & $0,17-0,20$ & $0,27 \pm 0,07$ & $0,26-0,29$ \\
\hline $\mathrm{Q}_{\mathrm{f}}, \mathrm{kcal} \cdot \mathrm{min}^{-1} \cdot \mathrm{kg}^{-1}$ & $0,04 \pm 0,04$ & $0,03-0,05$ & $0,00 \pm 0,01$ & $0,00-0,01$ \\
\hline
\end{tabular}

As can be seen from Table 2, the standard deviation of the fat utilization rate when reaching the AT is equal to the average value, which indicates a large variability in the values of this indicator.

For the VO2max level, the value of the quadratic deviation Qf is associated with isolated recorded cases of $\mathrm{VO}_{2 \max }$ achievement with RER of less than 1.

In order to determine whether these differences in muscle metabolism affect the metabolic reserves and performance of athletes, we performed a correlation analysis (Table 3 ).

Table 3

Significant $(p<0.05)$ correlation between energy consumption, contribution of energy supply substrates and capacity at $\mathrm{AT}$ and $\mathrm{VO}_{2 \max }$

\begin{tabular}{|c|c|c|c|c|c|}
\hline \multirow{2}{*}{\multicolumn{2}{|c|}{ Measurement }} & \multicolumn{2}{|c|}{ AT } & \multicolumn{2}{|c|}{$\mathrm{VO}_{2}$} \\
\hline & & $\begin{array}{c}\mathrm{VO}_{2}, \\
\mathrm{ml} \cdot \mathrm{min}^{-1} \cdot \mathbf{k g}^{-1}\end{array}$ & $\begin{array}{c}\text { Power output, } \\
W \cdot \mathrm{kg}^{-1}\end{array}$ & $\begin{array}{c}\mathrm{VO}_{2}, \\
\mathrm{ml} \cdot \mathrm{min}^{-1} \cdot \mathrm{kg}^{-1}\end{array}$ & $\begin{array}{l}\text { Power output, } \\
W \cdot \mathrm{kg}^{-1}\end{array}$ \\
\hline & $\mathrm{RER}_{\text {rest }}$ & $-0,21 *$ & $-0,16^{*}$ & $-0,26$ & $-0,17 *$ \\
\hline \multirow{4}{*}{ AT } & $\mathrm{RER}_{\mathrm{AT}}$ & $-0,13 *$ & $0,02 *$ & $-0,22$ & $-0,02 *$ \\
\hline & $\mathrm{Q}, \mathrm{kcal} \cdot \mathrm{min}^{-1} \cdot \mathrm{kg}^{-1}$ & 0,97 & 0,78 & 0,84 & 0,67 \\
\hline & $\mathrm{Q}_{c}, \mathrm{kcal} \cdot \mathrm{min}^{-1} \cdot \mathrm{kg}^{-1}$ & 0,60 & 0,56 & 0,45 & 0,45 \\
\hline & $\mathrm{Q}_{\mathrm{f}}, \mathrm{kcal} \cdot \mathrm{min}^{-1} \cdot \mathrm{kg}^{-1}$ & 0,30 & $0,15^{*}$ & 0,37 & $0,18^{*}$ \\
\hline \multirow{2}{*}{$\mathrm{VO}_{2 \max }$} & $\mathrm{Q}, \mathrm{kcal} \cdot \mathrm{min}^{-1} \cdot \mathrm{kg}^{-1}$ & 0,87 & 0,73 & 0,99 & 0,74 \\
\hline & $\mathrm{Q}, \mathrm{kcal} \cdot \mathrm{min}^{-1} \cdot \mathrm{kg}^{-1}$ & 0,82 & 0,70 & 0,95 & 0,72 \\
\hline
\end{tabular}

* Marked correlations are not significant at $\mathrm{p}<0,05$

We found that athletes with higher use of fat as an energy substrate at rest tend to more intensively use fat for energy at $\mathrm{AT}$ and $\mathrm{VO}_{2 \max }$ : The RER resting value has a reliable relationship with $\operatorname{RER}_{\mathrm{AT}}(\mathrm{r}=0.52, \mathrm{p} \leq 0.05)$ and $\mathrm{RER}_{\mathrm{VO} 2 \max }(\mathrm{r}=0.52, \mathrm{p} \leq 0.05)$. An even greater reliable relationship was found between the $\mathrm{RER}_{\mathrm{AT}}$ and the $\mathrm{RER}_{\mathrm{vO2 \operatorname {max }}}(\mathrm{r}=0.86, \mathrm{p} \leq 0.05)$. 
In addition, there is a relationship between resting metabolic efficiency and $\mathrm{VO}_{2 \max }$ $(\mathrm{r}=-0.26, \mathrm{p} \leq 0.05)$. Athletes with higher metabolic efficiency at rest have the advantage of using different sources of energy during intense muscular activity. In the case of efficient use of fat as a substrate of energy at rest, the share of their contribution to energy supply remains significant (up to $37 \%$ ) even when reaching the AT.

Table 4

Body composition, energy expenditure and level of performance in athletes with different metabolic efficiency at rest $(\mathrm{X} \pm \partial ; 95 \% \mathrm{CI})$

\begin{tabular}{|c|c|c|c|c|}
\hline \multirow{2}{*}{ Conditions } & \multirow{2}{*}{ Measurement } & \multicolumn{3}{|c|}{ Groups } \\
\hline & & $1(n=56)$ & $2(n=17)$ & $3(n=26)$ \\
\hline \multirow{4}{*}{ 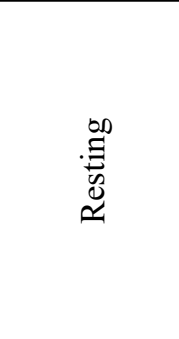 } & Body mass, $\mathrm{kg}$ & $\begin{array}{c}75,02 \pm 11,28 \\
(72,00-78,04)\end{array}$ & $\begin{array}{c}78,56 \pm 13,44 \\
(71,65-85,47)\end{array}$ & $\begin{array}{c}79,33 \pm 10,74 \\
(74,99-83,67)\end{array}$ \\
\hline & LBM, kg & $\begin{array}{c}66,56 \pm 8,55 \\
(64,27-68,85)\end{array}$ & $\begin{array}{c}69,00 \pm 10,78 \\
(63,46-74,54) \\
\end{array}$ & $\begin{array}{c}70,72 \pm 8,34 \\
(67,35-74,08)\end{array}$ \\
\hline & Fat, $\%$ & $\begin{array}{c}10,53 \pm 3,78 \\
(9,51-11,54)\end{array}$ & $\begin{array}{c}11,92 \pm 3,11 \\
(10,32-13,51)\end{array}$ & $\begin{array}{c}10,64 \pm 2,93 \\
(9,45-11,82)\end{array}$ \\
\hline & RER * & $\begin{array}{c}0,74 \pm 0,06 \\
(0,73-0,76)\end{array}$ & $\begin{array}{c}0,85 \pm 0,01 \\
(0,84-0,86)\end{array}$ & $\begin{array}{c}0,94 \pm 0,06 \\
(0,91-0,96)\end{array}$ \\
\hline \multirow{6}{*}{ AT } & RER ** & $\begin{array}{c}0,93 \pm 0,05 \\
(0,92-0,94)\end{array}$ & $\begin{array}{c}0,99 \pm 0,06 \\
(0,95-1,08)\end{array}$ & $\begin{array}{c}1,00 \pm 0,07 \\
(0,97-1,03)\end{array}$ \\
\hline & Oxygen uptake, $\mathrm{ml} \cdot \mathrm{min}^{-1} \cdot \mathrm{kg}^{-1}$ & $\begin{array}{c}48,30 \pm 8,84 \\
(45,94-50,67) \\
\end{array}$ & $\begin{array}{c}44,76 \pm 6,84 \\
(41,24-48,28) \\
\end{array}$ & $\begin{array}{c}45,40 \pm 9,01 \\
(41,76-49,04) \\
\end{array}$ \\
\hline & Power output, $\mathrm{W} \cdot \mathrm{kg}^{-1}$ & $\begin{array}{c}3,31 \pm 0,93 \\
(3,06-3,56)\end{array}$ & $\begin{array}{c}3,35 \pm 0,94 \\
(2,87-3,84)\end{array}$ & $\begin{array}{c}3,06 \pm 1,02 \\
(2,63-3,49)\end{array}$ \\
\hline & $\mathrm{Q}, \mathrm{kcal} \cdot \mathrm{min}^{-1} \cdot \mathrm{kg}^{-1}$ & $\begin{array}{c}0,24 \pm 0,05 \\
(0,23-0,25)\end{array}$ & $\begin{array}{c}0,22 \pm 0,03 \\
(0,21-0,24)\end{array}$ & $\begin{array}{c}0,23 \pm 0,05 \\
(0,21-0,24)\end{array}$ \\
\hline & $\mathrm{Q}_{\mathrm{c}}, \mathrm{kcal} \cdot \mathrm{min}^{-1} \cdot \mathrm{kg}^{-1}$ & $\begin{array}{c}0,18 \pm 0,05 \\
(0,17-0,20)\end{array}$ & $\begin{array}{c}0,20 \pm 0,05 \\
(0,18-0,23)\end{array}$ & $\begin{array}{c}0,20 \pm 0,05 \\
(0,18-0,22)\end{array}$ \\
\hline & $\mathrm{Q}_{\mathrm{f}}, \mathrm{kcal} \cdot \mathrm{min}^{-1} \cdot \mathrm{kg}^{-1 * *}$ & $\begin{array}{c}0,06 \pm 0,04 \\
(0,05-0,07)\end{array}$ & $\begin{array}{c}0,02 \pm 0,03 \\
(0,01-0,04)\end{array}$ & $\begin{array}{c}0,02 \pm 0,03 \\
(0,01-0,03)\end{array}$ \\
\hline \multirow{6}{*}{$\mathrm{VO}_{2 \max }$} & RER ** & $\begin{array}{c}1,05 \pm 0,06 \\
(1,04-1,07)\end{array}$ & $\begin{array}{c}1,12 \pm 0,11 \\
(1,06-1,17)\end{array}$ & $\begin{array}{c}1,15 \pm 0,09 \\
(1,12-1,19)\end{array}$ \\
\hline & Oxygen uptake, $\mathrm{ml} \cdot \mathrm{min}^{-1} \cdot \mathrm{kg}^{-1}$ & $\begin{array}{c}58,66 \pm 9,52 \\
(56,11-61,20)\end{array}$ & $\begin{array}{c}54,47 \pm 9,08 \\
(49,80-59,13)\end{array}$ & $\begin{array}{c}54,71 \pm 8,28 \\
(51,37-58,06)\end{array}$ \\
\hline & Power output, $\mathrm{W} \cdot \mathrm{kg}^{-1}$ & $\begin{array}{c}4,50 \pm 1,31 \\
(4,14-4,85)\end{array}$ & $\begin{array}{c}4,62 \pm 1,46 \\
(3,86-5,37) \\
\end{array}$ & $\begin{array}{c}4,13 \pm 1,41 \\
(3,54-4,72) \\
\end{array}$ \\
\hline & $\mathrm{Q}, \mathrm{kcal} \cdot \mathrm{min}^{-1} \cdot \mathrm{kg}^{-1}$ & $\begin{array}{c}0,30 \pm 0,05 \\
(0,28-0,31) \\
\end{array}$ & $\begin{array}{c}0,28 \pm 0,05 \\
(0,25-0,30) \\
\end{array}$ & $\begin{array}{c}0,27 \pm 0,04 \\
(0,26-0,29) \\
\end{array}$ \\
\hline & $\mathrm{Q}_{\mathrm{c}}, \mathrm{kcal} \cdot \mathrm{min}^{-1} \cdot \mathrm{kg}^{-1}$ & $\begin{array}{c}0,29 \pm 0,05 \\
(0,28-0,30)\end{array}$ & $\begin{array}{c}0,27 \pm 0,05 \\
(0,25-0,30)\end{array}$ & $\begin{array}{c}0,27 \pm 0,04 \\
(0,26-0,29)\end{array}$ \\
\hline & $\mathrm{Q}_{\mathrm{f}}, \mathrm{kcal} \cdot \mathrm{min}^{-1} \cdot \mathrm{kg}^{-1}$ & $\begin{array}{c}0,01 \pm 0,01 \\
(0,00-0,01)\end{array}$ & $\begin{array}{c}0,003 \pm 0,01 \\
(-0,002-0,008)\end{array}$ & $\begin{array}{l}0,00 \pm 00,00 \\
(0,00-0,01)\end{array}$ \\
\hline
\end{tabular}

* Difference is significant between all groups (Tukey honestly significant difference, $p \geq 0.05$ ) ** Difference is significant between 1st group and 2nd group, and 1st group and 3rd group (Tukey honest significant difference, $\mathrm{p} \geq 0.05$ ) 
As significant variability was found between the indicators of resting RER in the surveyed athletes, the athletes were divided into 3 groups according to their RER in order to determine the value of metabolic efficiency for the metabolic reserve (Table 4):

Group $1-$ RER $\leq 0.82$ (energy supply from fat $-60 \%$ and more)

Group 2 - RER 0.83-0.87 (energy supply from fat - 44-58\%)

Group $3-$ RER $\geq 0.88$ (energy supply from fat $41 \%$ and below)

As can be seen from the Table 4, the groups are homogeneous in body weight and composition. Differences in resting RER values are significant between all groups. The greater contribution of fat to energy production in athletes of the first group has been established not only at rest, but also during exercise. Thus, significantly lower values of RER were registered when reaching $\mathrm{AT}$ and $\mathrm{VO}_{2 \max }$. The contribution of fat to energy supply was substantive during exercise at the level of the anaerobic threshold in athletes with the highest metabolic efficiency. Thus, the contribution of fat to the energy supply when reaching AT was $24 \%$ for athletes of the 1 st group; $4 \%$ for the 2 nd group and $0 \%$ for the 3 rd group.

It is worth noting the fact that oxygen consumption was higher in athletes with the highest metabolic efficiency (group 1) both when achieving AT and $\mathrm{VO}_{2 \max }$. So $\mathrm{VO}_{2}$ averaged 48.3; 44.8 and $45.4 \mathrm{ml} \cdot \mathrm{min}^{-1} \cdot \mathrm{kg}^{-1}$, respectively, in groups 1,2 , and 3 when reaching AT and 58,6; 54.5 and $57.7 \mathrm{ml} \cdot \mathrm{min}^{-1} \cdot \mathrm{kg}^{-1}$ when reaching $\mathrm{VO}_{2 \max }$. These differences in $\mathrm{VO}_{2}$ values are not significant. At the same time, this fact needs further research, as the study revealed a significant correlation between the efficiency of metabolism $\left(\right.$ RER $_{\text {rest }}$ and RER $_{\mathrm{AT}}$ ) and maximum oxygen consumption (Table 3 ).

\section{Discussion}

The study found a link between RER and the use of energy substrates at rest and when achieving AT and $\mathrm{VO}_{2 \max }$ in the athletes. The largest range of RER differences is registered at rest. Thus, the coefficient of variation was $12.3 \%, 7.3 \%$ and $8.3 \%$, respectively, at rest, when reaching AT and $\mathrm{VO}_{2 \max }$. The variability at the level of AT and $\mathrm{VO}_{2 \max }$ is lower, as the contribution of carbohydrates to energy production increases, but the differences in the use of fat between groups with different metabolic efficiencies persist. It should be noted that for untrained people at rest is characterized by RER 0.85 , which corresponds to the use as energy substrates of $49 \%$ carbohydrates and $51 \%$ fat (Shils\&Shike, 2006). In athletes at rest, the RER averaged $0.81 \pm 0.10$, which reflects the use of $65 \%$ of energy from fat. Such differences indicate a greater efficiency of metabolism of skilled athletes at rest.

Increasing the efficiency of metabolism in skilled athletes at rest plays a significant role during intense exercise, as evidenced by the established in this study a significant correlation between RER at rest and when achieving AT and $\mathrm{VO}_{2 \max }$ (for both $\mathrm{r}=0.52, \mathrm{p} \leq 0,05$ ). This fact indicates the importance of increasing the contribution of fat to energy for the more efficient use of glycogen stores during intense and especially long-term muscle activity.

Restoration of energy and substrate resources in the athlete's muscular activity is important to ensure his special performance: it is known that the duration of training can exceed 6 hours a day with energy expenditures that can exceed 10,000 kcal and while internal glycogen stores are limited, so the use of fat as a substrate of energy is of great importance (Seebohar, 2014). Thus, increasing metabolic efficiency can increase the energy supply of muscle activity, and thus increase metabolic reserves while reducing glycogen expenditure.

Given the limited amount of carbohydrate reserves on the one hand and the duration of training and competitive activities on the other, the efficient use of fat can be of particular 
importance for maintaining efficiency. This is confirmed by the reliable relationship between RER at the level of the anaerobic threshold and $\operatorname{RER}_{\text {vo2max }}(r=0.86, p \leq 0.05)$. The efficiency of metabolism significantly affects the values of $\mathrm{VO}_{2 \max }$ and the use of fat as a substrate of energy during intense exercise. This fact deserves special attention because the use of fat as a substrate of energy can play a crucial role in increasing metabolic reserves and prevent glycogen depletion, which allows for the delayed development of fatigue.

For comparison, in the case of the same glycogen stores in athletes of the 1st group when performing the exercise load at the level of the anaerobic threshold, they will be enough for 120 minutes, for 102 minutes in the second group, and for 99 minutes for the 3rd. Therefore, with the same level of metabolic and other reserves, with efficient metabolism, athletes can extend the duration of intense exercise, which is especially important for sports with a predominant manifestation of endurance.

It is clear that creating conditions for maintaining the efficiency of metabolism is one of the ways to increase metabolic reserves and possibly increase the special performance of skilled athletes, as well as to increase the duration of intense exercise and delay the manifestations of decompensated fatigue during training and competition. As the data obtained in the study indicate a close, reliable relationship between metabolic efficiency at rest and during exercise of varying intensity, the determination of respiratory exchange ratio is appropriate to assess the metabolic reserves of qualified athletes.

This study is not without limitations. With an RER above AT, it is impossible to accurately determine the contribution of fat to energy supply, because the value of RER in this state is significantly affected by non-metabolic $\mathrm{CO}_{2}$ increase. However, the relationship between lower $\mathrm{RER}_{\text {rest }}$ and lowering values of $\mathrm{RER}_{\mathrm{AT}}$ and $\mathrm{RER}_{\mathrm{vO2max}}$ allows us to assess this value indirectly. The results of the study would be more significant in practice if the nutrition of athletes is taken into account, which may also affect the efficiency of metabolism. However, the aim of this study was to investigate the efficiency of metabolism in a relatively large sample. Assessment of the impact of nutrition on metabolic efficiency a promising area of further research.

\section{Conclusions}

1. Metabolic efficiency is an important component of metabolic reserves and sports performance in athletes with the predominant manifestation of endurance. Efficient resting metabolism creates the preconditions for more efficient use of energy substrates during intense muscle activity.

2. The respiratory exchange ratio in skilled athletes at rest significantly correlates with the values of RER when reaching the anaerobic threshold and $\mathrm{VO}_{2 \max }$ and with the maximum oxygen consumption.

3. The respiratory exchange ratio is an informative indicator of the efficiency of metabolism, which can be used in the complex control of the functional state of the athlete.

\section{Conflict of interest}

The author reports no conflicts of interest associated with this manuscript. 


\section{References}

Bergman, B. C., \& Brooks, G. A. (1999). Respiratory gas-exchange ratios during graded exercise in fed and fasted trained and untrained men. Journal of Applied Physiology, 86(2), 479-487. doi:10.1152/jappl.1999.86.2.479

Burke, L., Deakin, V., \& Allanson, B. (2015). Clinical sports nutrition. North Ryde, N.S.W, Australia : McGraw-Hill Education (Australia) Pty Ltd.

Carpenter, T. M. (1964). Tables, factors, and formulas for computing respiratory exchange and biological transformations of energy. Washington, D.C.: Carnegie institution of Washington.

Carter, S. L., Rennie, C., \& Tarnopolsky, M. A. (2001). Substrate utilization during endurance exercise in men and women after endurance training. American Journal of Physiology-Endocrinology and Metabolism, 280(6). doi:10.1152/ajpendo.2001.280.6.e898

Coggan, A. R., Raguso, C. A., Gastaldelli, A., Sidossis, L. S., \& Yeckel, C. W. (2000). Fat metabolism during high-intensity exercise in endurance-trained and untrained men. Metabolism, 49(1), 122-128. doi:10.1016/s0026-0495(00)90963-6

Goedecke, J. H., Gibson, A. S., Grobler, L., Collins, M., Noakes, T. D., \& Lambert, E. V. (2000). Determinants of the variability in respiratory exchange ratio at rest and during exercise in trained athletes. American Journal of Physiology-Endocrinology and Metabolism, 279(6). doi:10.1152/ajpendo.2000.279.6.e1325

Helge, J., Fraser, A., Kriketos, A., Jenkins, A., Calvert, G., Ayre, K., \& Storlien, L. (1999). Interrelationships between muscle fibre type, substrate oxidation and body fat. International Journal of Obesity, 23(9), 986-991. doi:10.1038/sj.ijo.0801030

Jeukendrup, A. E., Mensink, M., Saris, W. H., \& Wagenmakers, A. J. (1997). Exogenous glucose oxidation during exercise in endurance-trained and untrained subjects. Journal of Applied Physiology, 82(3), 835-840. doi:10.1152/jappl.1997.82.3.835

Klein, S., Coyle, E. F., \& Wolfe, R. R. (1994). Fat metabolism during low-intensity exercise in endurance-trained and untrained men. American Journal of Physiology-Endocrinology and Metabolism, 267(6). doi:10.1152/ajpendo.1994.267.6.e934

Messonnier, L., Denis, C., Prieur, F., \& Lacour, J. (2005). Are the effects of training on fat metabolism involved in the improvement of performance during high-intensity exercise? European Journal of Applied Physiology, 94(4), 434-441. doi:10.1007/s00421-005-1325-4

Pendergast, D. R., Leddy, J. J., \& Venkatraman, J. T. (2000). A Perspective on Fat Intake in Athletes. Journal of the American College of Nutrition, 19(3), 345-350. doi:10.1080/0731572 4.2000.10718930

Rauch, H., Hawley, J., Woodey, M., Noakes, T., \& Dennis, S. (1999). Effects of Ingesting a Sports Bar Versus Glucose Polymer on Substrate Utilisation and Ultra-Endurance Performance. International Journal of Sports Medicine, 20(04), 252-257. doi:10.1055/s-2007-971126 Romijn, J. A., Coyle, E. F., Sidossis, L. S., Rosenblatt, J., \& Wolfe, R. R. (2000). Substrate metabolism during different exercise intensities in endurance-trained women. Journal of Applied Physiology, 88(5), 1707-1714. doi:10.1152/jappl.2000.88.5.1707

Seebohar, B. (2014). Metabolic efficiency training: Teaching the body to burn more fat (2nd ed.). USA: Fuel4mance ${ }^{\circledR}$, LLC.

Shils, M. E., \& Shike, M. (2006). Modern nutrition in health and disease. Philadelphia, PA: Lippincott Williams \& Wilkins.

Spriet, L. L. (2002). Regulation of skeletal muscle fat oxidation during exercise in humans. Medicine \& Science in Sports \& Exercise, 34(9), 1477-1484. doi:10.1097/00005768-200209 000-00013 